NBER WORKING PAPER SERIES

\title{
RISK SHIFTING, UNEMPLOYMENT INSURANCE, AND LAYOFFS
}

Herschel I. Grossman

Working Paper No. $\underline{424}$

\author{
NATIONAL BUREAU OF ECONOMIC RESEARCH \\ 1050 Massachusetts Avenue \\ Cambridge MA 02138 \\ January 1980
}

\begin{abstract}
Presented at Conference on the Labour Market, sponsored by Treasury, Department of Baployment, and Manpower Services Commission, at Magdalen College, Oxford, September 10-12, 1979. The National Science Foundation and the John Simon Guggenheim Memorial Foundation have supported this research. Dale Mortensen gave me a number of useful suggestions. This paper will appear in the forthcoming volume, The Economics of the Labour Market, (HMSO, London). The research reported here is part of the NBER's research program in Labor Studies. Any opinions expressed are those of the author and not those of the National Bureau of Economic Research.
\end{abstract}


NBER Working Paper \#424

December, 1979

\section{Risk Shifting, Unemployment Insurance, and Layoffs}

\section{ABSTRACT}

This paper develops an analysis of labor markets in which the use of layoffs to effect employment separations does not imply that markets fail to clear or that the amount of employment is suboptimal relative to current perceptions. This analysis focuses on the interaction between contractual arrangements for shifting risk from workers to employers and tax-financed unemployment insurance. The key element in the analysis is that unemployment insurance is more attractive than risk shifting as a way for workers to obtain income during unemployment. The paper also analyses the effects of risk shifting and unemployment insurance on the magnitude of employment fluctuations. The analysis implies that, given the existence of unemployment insurance, the existence of risk-shifting arrangements makes employment less variable.

Professor Herschel I. Grossman Department of Economics Brown University Providence, RI 02912 (401) 863-2606 
1. A Market-Clearing Model of Layoffs

The observation that cyclical fluctuations in real variables such as aggregate employment appear to reflect predominately the effects of changes in aggregate demand for output poses two critical questions for macroeconomics. First, what are the causes of fluctuations in aggregate demand? Second, why do these fluctuations produce cycles in real variables, rather than being absorbed by price and wage adjustments as would be the case in a walrasian model of general equilibrium?

A broad concensus, which emerged at least a decade ago, seems presently to prevail about the many issues associated with the first question, concerned with the determinants of aggregate demand. For example, there seems to be little active current discussion about the relative influence that monetary factors, fiscal actions, and endogenous phenomena have on aggregate demand. Recent years, however, have seen intense research interest and associated controversy directed towards the second question, concerned with identifying the characteristics of the actual economy that are responsible for the non-Walrasian responses of real variables to cycles in aggregate demand.

One popular approach, describable as Keynesian, has been to attribute the causal relation between aggregate demand and aggregate employment to a failure of wages and prices to adjust to equate quantities demanded and supplied in labor and product markets. An essential aspect of this interpretation of the process of employment fluctuation is that a contraction in employment resulting from a reduction in aggregate demand involves a situation in which perceived gains from trade are foregone. A frequent criticism of this non-market-clearing paradigm has been that the theoretical development in the existing literature provides no convincing rationale, based on neoclassical premises, for such a persistent 
failure to realize perceived gains from trade. For example, in the book by Barro and myself, the determination of the vector of wages and prices at which buyers and sellers are constrained to transact is based on ad hoc gradual adjustment processes. The choicetheoretic analysis is concerned mainly with the implications of such essentially arbitrarily specified wage-price vectors for the determination of employment. Some other models rationalize gradual wage and price adjustment on the basis of adjustment costs, which is logically adequate, but convincing stories about the precise nature of these costs do not seem to exist.

Despite this problem, the non-market-clearing paradigm has remained popular primarily because it has seemed to be realistic. The analysis in the present paper questions the accuracy of this impression. It suggests that the prevalence of layoffs as a mode of employment separation does not provide evidence of chronic failure of labor markets to clear and that the conventional view that in cyclical contractions workers typically confront excess supply in labor markets and are unable to obtain desired employment may involve a misinterpretation of the facts.

The basis for this revisionist argument is the recent theoretical development of the hypothesis that actual labor market transactions typically involve implicit contractual arrangements that stabilize worker income by shifting risk from workers to employers. This hypothesis suggests the possibility of rationalizing stickiness of wage rates and explaining the alleged symptoms of non-wage rationing of employment, such as layoffs, without invoking the failure of markets to clear.

The main specific objective of the present paper is to develop an analysis of labor markets in which the use of layoffs to effect employment separations does not imply that the amount of employment is suboptimal relative to current 
perceptions. This analysis suggests that the non-Walrasian causal relation between aggregate demand and aggregate employment results not from the failure of markets to clear, but from misperceptions of the terms of trade between labor services and consumption goods, as hypothesized by Friedman (1968), Lucas (1975), and others, and integrated into a model of risk shifting by Azariadis (1968). Having focussed on these alternative explanations, it is worth stressing that non-Walrasian fluctuations in employment in either case are wasteful and undesirable, whether they result from the failure to realize perceived gains from trade or from the failure to perceive gains from trade correctly.

The risk-shifting hypothesis plays a critical part in the present analysis, but by itself does not provide a full account within a market-clearing framework of the diverse phenomena associated with layoffs. An adequate analysis of layoffs seems to require, in addition, explicit allowance for the consequences of tax-financed unemployment insurance.

A second specific objective of this paper is to use the model that incorporates both risk shifting and unemployment insurance to reconsider previous analysis of the effects of risk shifting on the magnitude of employment fluctuations. The present analysis shows that the quantitative effects of risk shifting and unemplcymentinsurance are not additive. When analyzed separately, both risk-shifting arrangements and unemployment insurance seem to magnify employment fluctuations by increasing the responsiveness of labor supply to shifts in labor's perceived real compensation. However, in the analysis below, the introduction of risk shifting into a model that allows for unemployment insurance has the opposite effect of reducing employment fluctuations. 
2. Layoffs as a Mode of Employment Separation

Before reviewing recent analyses of risk shifting and unemployment insurance, it will be useful to have clearly in mind the characteristics of layoffs as a mode of employment separation. Layoffs involve the following four phenomena:

(PI) Employers follow the administrative procedure of assigning workers to the status of unemployment. Thus, the term "layoff" in the present discussion refers broadly to any separation, i.e., suspension or termination of employment, that the employer initiates. In other words, the status of being laid off denotes a proximately passive role for the worker in becoming unemployed. For simplicity, the analysis below also implicitly assumes that a worker who is laid off is available to return to work whenever his employer recalls him. However, extending the analysis to allow workers to choose to change jobs would not alter the main conclusions. (P2) When employers lay off some workers, presumably indicating a decrease in the demand for labor services, they typically do not reduce wage rates for those other workers who continue to be employed. This practice seems inconsistent with the neoclassical inclination to view wage rates as changing to equate quantities of labor services supplied and demanded.

(P3) Workers who are laid off usually receive no income from their employers. In this respect, a layoff is not different from other modes of job separation.

(P4) Employers typically use seniority classifications to determine which workers are laid off. In practice, a worker's seniority classification depends mainly on his length of service with a particular employer, but can also depend on other factors, a frequent one being his age. As the following discussion indicates, rationalizations for (PI) and (P4) have not been hard to invent, but no single approach has been able to account readily for both (P2) and (P3). 
3. Summary of Recent Literature

The essential idea in the theory of risk shifting in labor markets is that a systematic difference between firms and their workers with regard to risk aversion leads to long-term commitments in which the firms absorb risk that would otherwise be borne by the workers. These commitments imply that actual relations between firms and workers implicitly involve two transactions. First, firms purchase from workers labor services for use in the production process and, second, firms sell to workers private insurance against undesirable income fluctuations. Workers engage in these transactions jointly with a single firm, instead of selling labor services to one firm and buying insurance from another, because the production relation between firms and workers mitigates the problems of monitoring and enforcement that arise in the insurance relation. As a result of these contractual arrangements, a worker's wage income equals either the value of his marginal contribution to output minus an implicit insurance premium or the value of his marginal contribution to output plus an implicit insurance indemnity, depending on whether the perceived real value of labor's marginal product, which is a stochastic variable, is high or low.

Risk shifting in effect credits part of the value of product when it is high to an implicit premium that yields an implicit indemnity when the value of product is low. This arrangement enables the worker to use product generated in states in which consumption would otherwise be high to boost consumption in states in which consumption would otherwise be low. Consequently, risk shifting increases the attractiveness of working when the value of product is high and decreases the pressure to work when the value of product is low relative to what would be the case if income and consumption in each state were equal to the value of product in that state. This reasoning explains the result, derived in Azariadis (1978) and Grossman (1978), that risk shifting makes the level of employment more variable. 
Turning to the characteristics of layoffs, the idea that labor market transactions involve risk shifting has provided what seems to be the only choice-theoretic explanation for (P2), the surprising wage rate stickiness associated with layoffs. The basic observation is that the insurance aspect of labor contracts serves to stabilize worker income and, thus, explains why reductions in the quantity of employment typically do not also involve reductions in wage rates.

The relation between risk shifting and productive efficiency also suggests a simple explanation for (PI), the administrative procedures associated with layoffs. Efficiency requires that a worker be employed in a particular state of nature if the utility associated with being employed and receiving the value of his marginal contribution to total product equals or exceeds the utility associated with not being employed. However, with risk shifting in effect, a worker's wage income does not equal the value of his. marginal contribution to total product. As a result, his wage income cannot serve, as would the wage rate in a spot market, to signal the worker as to whether it is efficient for him to accept or to reject employment. Consequently, . in order to achieve efficiency, the implicit labor contracts must specify each worker's employment status as a function of the perceived real value of his marginal product. Moreover, in order to economize on the costs of acquiring and processing information, the contracts delegate to the employer the administrative function of assigning workers to employment or unemployment.

Despite the essential nature of these insights, the basic analysis of risk shifting has the problem that it seems to imply too much. Specifically, it does not allow for (P3) 
and (P4), the failure of employers to provide a constant, fully insured income for all workers.

The model in Grossman (1978) attempts to remedy this problem by allowing for incompleteness and inter-worker differences in risk shifting. This extended model rationalizes ( $P 4)$, the role of seniority in determining the incidence of layoffs by assuming that worker productivity increases with age and with length of service with a particular employer. In addition, in an attempt to account for (P3), the fact that laid-off workers typically receive no indemnity income from their employers, this model assumes the worker reliability is related to seniority. The problem of worker unreliability results from the possibility that the prospect of short-run gains, when the value of their marginal contributions to output are high, can induce workers to quit their jobs. Differences between more and less senior workers in their reputations for reliability, which relate to their behavior when the perceived real value of marginal product is high, produce differences in the terms at which they can obtain income when the perceived real value of marginal product is low. specifically, less senior workers, whose average reliability is low, contract for less stable incomes.

Whatever the actual importance of reliability considerations, the correspondence between the implications of this model and (P3) is unfortunately less than completely tight. Specifically, the model provides no reason why lower seniority classes should purchase from their employer exactly zero insurance against reduced income in those instances when productive efficiency dictates that they be unemployed. 
The effects of tax-financed unemployment insurance on the variability of employment are similar to the effects of risk shifting. The existence of unemployment insurance increases the attractiveness of working when the value of product is high because a worker both earns his wage income and becomes eligible for unemployment insurance benefits and decreases the attractiveness of working when the value of product is low because benefits make unemployment more tolerable.

With regard to the characteristics of layoffs, the key characteristics of unemployment insurance are that an unemployed worker can receive benefits only if his unemployment is "involuntary" and that the amount of these benefits are reduced by the amount of any other income that the worker receives when unemployed. These eligibility rules provide inducements for (PI), by which firms take proximate responsibility for job separations, and for (P3), the discontinuance of income $\therefore$ payments by firms to laid off workers. In adaition, in this context, as in the analysis of risk-shifting arrangements, the association of productivity with seniority can readily account for ( $P 4)$, the role of seniority in determining the incidence of layoffs.

The existence of unemployment insurance, however, provides no explanation for $P(2)$, the constancy of wages for employed workers. Existing theoretical models of the effects of unemployment insurance--for example, Baily (1977) and. Feldstein (1976)--simply introduce (P2) as a realistic assumption. However, (P2) is the only qualitative economic feature of layofis that is clearly distinctive. In contrast, (PI) is only an administrative procedure and (P3) and (P4) are not peculiar to layoffs as a mode of job separation. Thus, the inability to account for (P2) is a critical problem. 
Another possible objection to focusing on unemployment insurance is that the use of the layoff mode to effect employment separations has not been historically associated with the advent of the current centrally administered programs of income maintenance for the unemployed. However, this objection is not serious if the eligibility rules and financing arrangements of earlier privately and locally administered incomemaintenance programs generated the same incentives as current programs.

To summarize, existing analysis suggests that both risk shifting and tax-financed unemployment insurance increase the variability of employment. However, neither models of risk shifting nor models of unemployment insurance can readily explain the full set of phenomena associated with layoffs as a mode of employment separation. The following sections show that analysis of the interaction between risk shifting and unemployment -insurance both alters this conclusion about the effect of risk shifting on employment fluctuations and also produces a more satisfactory theory of layoffs.

4. Analytical Framework

The simple economy analyzed in this paper differs from the setup in Grossman (1978) by allowing for unemployment insurance but abstracting from reliability considerations. In this economy, there are two large groups of individuals that differ in their attitudes to risk. One large group of identical individuals behaves in a less risk averse, or even risk neutral, manner. These individuals choose the role of entrepreneurs, who organize production by forming firms and employing inputs, including labor services. 
The second large group of individuals behave in a more risk averse manner. These individuals choose the role of employees, who work for the firms and provide labor services. As indicated above, this difference between the attitudes toward risk of entrepreneurs and workers provides the basis for risk-shifting arrangements.

The analysis assumes, for simplicity, that all workers have the same utility function, and that this utility function is additively separable in consumption and the amount of time devoted to employment. Consumption here refers to consumable commodities purchased in the market place and employment refers to working as an employee of a firm. Individuals can use time not devoted to employment for home production of other consumable commodities.

The analysis also assumes that labor services are "homogeneous and that each worker has only a single unit of time to devote to employment. It would seem fairly straightforward, although not essential for present purposes, to extend the analysis to take explicit account of variable hours of work.

A more important assumption is that individual workers differ with respect to the number of units of labor services that they provide per unit of employment time. The analysis assumes that the classification of potential workers according to age and length of service with a particular employer yields classes of increasing average productivity. It is convenient to index these seniority classes according to increasing seniority. Let the nonnegative variable $k_{i}$ denote the average productivity of the $i^{\text {th }}$ class of workers, where $k_{i}$ 
measures the average number of units of labor services provided by individuals in this class per unit of employment time. Thus, the lowest seniority class has the lowest $k_{i}$ and the highest seniority class has the highest $k_{i}$.

Workers exchange their labor services for consumption goods through a network of markets. Let $w$ denote the basic real wage rate, which is the perceived exchange ratio between consumption goods and a unit of labor services. Changes in $w$ represent perceived "real" disturbances, which is important because, as Barro (1977) has stressed, the productive efficiency of competitively determined contracts implies that in a contractual labor market, as in a spot market, disturbances perceived to be "monetary" would not affect employment. Competition in the contractual labor market insures that $w$ equals the perceived value of the marginal product of a unit of labor services. See Grossman (1978) for a derivation of this result. Whether or not the relevant perceptions are accurate does not matter for the present analysis.

From the standpoint of the workers, the variable $w$ is stochastic and is determined at periodic intervals by serially independent drawings from an exogenously determined population. The interval between these drawings defines a unit of time. The population of $w$ is such that

$$
w=\left\{\begin{array}{ccc}
w_{1} & \text { with probability } & \alpha_{1} \\
w_{2} & \text { with probability } & \alpha_{2}
\end{array}\right.
$$

where $w_{2}>w_{1}>0$ and $\alpha_{1}+\alpha_{2}=1$. Thus, $w_{2}$ characterizes a good state of nature and $w_{1}$ characterizes a bad state of nature. The assumption that there are only two states is a convenient simplification. See Grossman (1977) for a more general setup. In the rest of the paper, the subscripts 1 and 2 denote the values of each relevant variable in the two states. 
The analysis abstracts from the holding of assets--including investment goods, commodity inventories, and financial assets--by individuals. Allowing for the holding of either real or financial assets would make the analysis both more realistic and more complex, but would not seem to change the main conclusions. The key observation in this context is that, because the accumulation of assets involves foregoing consumption and because the probability is always positive that the next state will be bad, optimal worker or firm asset management would not involve using stocks of assets to achieve complete stability of worker consumption.

5. Employment Without Risk Shifting and Without Unemployment Insurance

In order to appreciate the significance of risk shifting and unemployment insurance and their interaction, this section begins the analysis by abstracting from these arrangements.

$\therefore$ This section and the next section, which allows for risk shifting, review relevant aspects of the analysis presented in Grossman (1978). Subsequent sections extend the analysis to consider unemployment insurance and the interaction between. risk shifting and unemployment insurance.

As indicated above, competition generates a vector of basic real wage rates, denoted by $\left(w_{1}, w_{2}\right)$, that are equal to the perceived value of the marginal product of a unit of labor services. Moreover, the standard theory of human capital tells us that in the present context, which among other things abstracts from training costs, employers could not take advantage of the firm specificity of their senior workers' productivity without impairing their-long-run ability to attract employees. Consequently, income possibilities for workers in the $i$ th class in the two possible states of nature are $w_{1} k_{i}$ and $w_{2} k_{i}$.

Given these income possibilities, each worker selects the vector of employment and wage income that maximizes his 
expected utility. In formulating this problem, the present analysis assumes that workers take a myopic view that abstracts from the dependence of productivity on the length of service. Thus, suppressing the subscript $i$, the worker's implicit problem is to choose the vector $\left(l_{1}, l_{2}, \Omega_{1}, \Omega_{2}\right)$, where $l$ measures units of employment time and $\Omega$ measures wage income, so as to maximize

$$
E(u-v)=\alpha_{1}\left[u\left(c_{1}\right)-v\left(l_{1}\right)\right]+\alpha_{2}\left[u\left(c_{2}\right)-v\left(l_{2}\right)\right],
$$

where $c$ measures worker consumption, $u(\cdot)$ is increasing and concave, and $\mathrm{v}(\cdot)$ is increasing and convex, subject to the constraints,

$$
\begin{aligned}
& \ell_{1}=\{0,1\}, \quad \ell_{2}=\{0, I\}, \quad c_{1}=\Omega_{1}, \quad c_{2}=\Omega_{2}, \\
& \Omega_{1}=w_{1} k l_{1}, \quad \text { and } \Omega_{2}=w_{2} k l_{2} .
\end{aligned}
$$

These constraints say that in each state consumption equals wage income and that wage income equals either the product of the basic wage rate and productivity if the worker chooses employment or zero if he chooses unemployment.

Depending on $\alpha_{1}, \alpha_{2}, w_{1}, w_{2}$, and $k$, the solution to this problem can prescribe for a particular worker employment either in both states, only in the good state, or in neither state. In choosing among these options, the worker selects the largest of the following possible values of $E(u-v)$ :

For employment in both states,

$$
E(u-v)=\alpha_{1} u\left(w_{1} k\right)+\alpha_{2} u\left(w_{2} k\right)-v(I) \equiv A(I, 1) .
$$

For employment only in the good state,

$$
E(u-v)=\alpha_{1} u(0)+\alpha_{2} u\left(w_{2} k\right)-\alpha_{1} v(0)-\alpha_{2} v(I) \equiv A(0,1) .
$$

For employment in neither state,

$$
E(u-v)=u(0)-v(0) \equiv A(0,0) \text {. }
$$


Comparison of these expected values reveals the following:

$$
\begin{aligned}
& A(1, I) \text { is largest iff } w_{1} k>z, \\
& A(0,1) \text { is largest iff } w_{1} k<z<w_{2} k \text {, and } \\
& A(0,0) \text { is largest iff } z>w_{2} k,
\end{aligned}
$$

where $z$ satisfies $u(z)=u(0)-v(0)+v(1)$.

This solution implies that a worker desires employment in a particular state of nature if his possible income in that state is sufficiently high to make the net utility associated with being employed and consuming this income at least as large as the net utility associated with not being employed and not consuming market goods.

The determination of which classes of workers are employed in each state of nature requires assumptions about the distribution of the $k_{i}$. Specifically, if $k_{a}$ is such that $w_{2} k_{a}=z$ and $k_{b}$, where $b>a$, is such that $w_{1} k_{b}=z$, workers in class $b$ and higher classes are employed in both states of nature and workers in classes a through b-l are employed only in the good state of nature. Individuals whose productivity is less than $\mathrm{k}_{\mathrm{a}}$ are not employed in either state.

An important aspect of this analysis that ignores risk shifting and unemployment insurance is that the basic wage rate varies from state to state in such a way that, in any state of nature in which a worker is employed, his income is equal to the value of his marginal contribution to output. Thus, each worker's income and consumption, whether or not he is employed in both states, is lower in the bad state than in the good state. In addition, the basic wage rate in each state of nature, which together with his productivity determines his potential income in each state, signals the worker as to whether or not the utility associated with being employed and receiving the value of his marginal contribution to output in that state equals or exceeds the utility associated with not being 
employed. In other words, the active decisions of workers to accept or reject employment lead to productive efficiency. Consequently, there is no need for the labor contracts to specify each worker's employment status as a function of the state of nature and, hence, no need for employers to take on the administrative task of assigning workers to employment or unemployment. In this context, adjustments in employment reflect solely wage-induced movements along the supply schedule of labor services and, except for the relation between employment and seniority, exhibit none of the characteristics associated with layoffs.

The observation that each worker, whether he is employed in both states or only in the good state, has higher consumption in the good state than in the bad state also suggests that the labor market in this analysis does not share risk in an efficient way. Specifically, the risk averse workers would prefer more predictable and stable consumption and the less riskaverse firms might be prepared to offer their workers a more predictable and stable income schedule.

\section{Risk Shifting}

This section introduces risk shifting, but continues to abstract from unemployment insurance. Risk shifting allows. each. worker's wage income in a particular state of nature to differ from the value of his marginal contribution to output in that state. As a result, efficient risk shifting can produce increased expected utility for the workers while at the same time producing an increase or no decrease in expected utility for the entrepreneurs.

Competition in the market for labor contracts that implicitly involve risk shifting generates, in addition to the basic real wage rates, an exchange ratio, denoted by $p$, at which workers give up income in the good state in return for income in the bad state. Risk shifting in effect provides the worker with additional income in state one equal to $\left(\Omega_{1}-w_{l} k_{l}\right)$ in exchange 
for a reduction in income in state two equal to $\left(w_{2} k l_{2}-\Omega_{2}\right)$. The price of risk shifting, $p$, is the ratio of the expected value of the reduction, $\alpha_{2}\left(w_{2} k l l_{2}-\Omega_{2}\right)$, to the expected value of the addition, $\alpha_{1}\left(\Omega_{1}-w_{1} k l_{1}\right)$.

A hypothetical value of $p$. equal to unity would characterized an actuarially "fair" price for risk shifting and would imply that workers could obtain a constant income at no cost to themselves in average income. Actually, we seem to observe that risk shifting reduces but does not eliminate income variability, even for workers who are employed in all states of nature. Specifically, although wage rates are sticky, they are not fixed. In addition, although not explicitly modelled in this paper, worker incomes vary with changes in hours of work.

These observations suggest that in fact $p$ exceeds unity, but is not so large as to make risk shifting unattrac- tive. According to the analysis in Grossman (1977; 1978), a value of $p$ above unity implies either that entrepreneurs are risk averse, or that $w_{2}$ is much larger than $w_{1}$, or that workers sometimes behave unreliably.

With risk shifting, the worker's problem is to choose the vector $\left(l_{1}, l_{2}, \Omega_{2}, \Omega_{2}\right)$ so as to maximize $E(u-v)$, subject to the constraints

$$
\begin{aligned}
& \ell_{1}=\{0,1\}, \quad \ell_{2}=\{0,1\}, \\
& c_{1}=\Omega_{1}, c_{2}=\Omega_{2}, \text { and } \\
& p \alpha_{1}\left(\Omega_{1}-w_{1} k l_{1}\right)=\alpha_{2}\left(w_{2} k l_{2}-\Omega_{2}\right) .
\end{aligned}
$$

This last constraint describes the terms of risk shifting. For example, for the special case of $p$ equal to unity, it would say that the worker can exchange with his employer income in the good state for income in the bad state subject only to the condition that the expected value of his income 
equals the expected value of his marginal contribution to output, which is equivalent to the expected value of the product of the basic wage rate, his productivity index, and his employment status.

We can describe the solution to this problem in two parts. One part says that, given his choice of employment in each state of nature, the worker allocates his income between the two states to satisfy the first-order condition

$$
u^{\prime}\left(c_{1}\right)=p^{\prime}\left(c_{2}\right),
$$

where $u^{\prime}(\cdot)$ is the marginal utility function. For the special case of $p$ equal to unity, this condition would imply that the worker sets $\Omega_{1}$ equal to $\Omega_{2}$, so that $c_{1}$ equals $c_{2}$, which means that his consumption is perfectly stable and predictable.

To obtain solutions for $\Omega_{1}$ and $\Omega_{2}$ for the case of $p$ greater than unity, consider a family of $u(c)$ functions that exhibit constant relative risk aversion. The members of this family are $u=(I-r)^{-1} c^{1-r}$ for $r \neq I$ and $u=l n c$ for $r=1$, where $r$ measures relative risk aversion. For this family, the above first-order condition becomes

$$
c_{2}=p^{1 / r} c_{1} \text {, }
$$

which, when substituted into the constraints, implies.

and

$$
\begin{aligned}
& \Omega_{1}=\frac{p \alpha_{1} w_{1} k l_{1}+\alpha_{2} w_{2} k l_{2}}{p \alpha_{1}+p^{1 / r} \alpha_{2}} \\
& \Omega_{2}=p^{1 / r} \Omega_{1} .
\end{aligned}
$$

The second part of the solution to the worker's problem says that, given the criterion for allocation of consumption between the two states, the worker determines his employment 
in each state. Depending now on $\alpha_{1}, \alpha_{2}, w_{3}, w_{2}, k$, and $p$, the worker again can choose employment in both states, only in the good state, or in neither state. In deciding among these options, the worker now selects the largest of the following possible values of $E(u-v)$ :

For employment in both states,

$$
E(u-v)=\alpha_{1} u\left(\frac{p \alpha_{1} w_{1} k+\alpha_{2} w_{2} k}{p \alpha_{1}+p^{1 / r} \alpha_{2}}\right)+\alpha_{2} u\left(p^{1 / r} \frac{p \alpha_{1} w_{1} k+\alpha_{2} w_{2} k}{p \alpha_{1}+p^{1 / r} \alpha_{2}}\right)-v(1) \equiv S(1,1
$$

For employment only in the good state,

$$
\begin{aligned}
E(u-v)= & \alpha_{1} u\left(\frac{\alpha_{2} w_{2} k}{p \alpha_{1}+p^{1 / r_{\alpha_{2}}}}\right)+\alpha_{2} u\left(\frac{p^{1 / r_{\alpha_{2}} w_{2} k}}{p \alpha_{1}+p^{1 / r_{\alpha_{2}}}}\right)-\alpha_{1} v(0)-\alpha_{2} v(1) \\
& \equiv \mathrm{s}(0,1) .
\end{aligned}
$$

For employment in neither state,

$\therefore \quad E(u-v)=u(0)-v(0) \equiv s(0,0)$.

In comparing the worker's options with and without risk shifting, observe that $S(0,0)$ is identical to $A(0,0)$, but that concavity of $u(\cdot)$ implies that $S(0,1)$ is larger than $A(0,1)$ and that $S(1,1)$ is larger than $A(1,1)$. Moreover, concavity of $u(\cdot)$ also implies that the value of $w_{1} k$ that is necessary and sufficient for $S(1,1)$ to be larger than $s(0,1)$ is larger than $z$ and is an increasing function of $w_{2} k$.

These results mean that risk shifting increases the range of combinations of $w_{1} k$ and $w_{2} k$ for which the worker chooses employment only in the good state and decreases the ranges of combinations of $\mathrm{w}_{2} \mathrm{k}$ and $\mathrm{w}_{2} \mathrm{k}$ for which the worker chooses employment in both states and neither state. Because risk shifting allows the worker to use the value of his marginal contribution to output in the good state to supplement his actual income and consumption in the bad state, the value of working in the good state is larger and he 
desires not to be employed in the good state only if $w_{2} k$ is sufficiently less than $z$. In addition, because risk shifting allows the worker to consume market goods in the bad state without working in the bad state, he desires to be employed in the bad state as well as in the good state only if $w_{1} k$ is sufficiently more than $z$. Moreover, the larger is $w_{2} k$, the larger has to be $w_{l} k$ for the worker to desire employment in both states.

As before, the determination of which workers are employed in each state of nature depends on the distribution of the $k_{i}$. Again, the higher productivity classes of workers choose contracts that specify employment in both states of nature, whereas lower productivity classes of workers choose contracts that specify employment only in the good state of nature, and the lowest productivity individuals are not employed in either state of nature. However, this analysis confirms that with risk shifting fewer classes of workers are employed in "both. states of nature and more classes of workers are employed in at least one state of nature. Both of these changes mean that more individuals now experience variable employment.

The most important implication of this section relating to phenomena associated with layoffs is that risk shifting gives all workers, including those who are employed in both states or only one state, less variable wage income. In addition, as noted above, an essential consequence of the shifting of risk from workers to firms is that a worker's contractual income does not equal the value of his marginal contribution to total product, and, hence, it does not serve, as would the wage rate in a spot auction market, to signal the worker as to whether or not it is efficient for him to accept employment. Thus, this analysis confirms that allowing for risk shifting readily accounts for (PI) and (P2) and is consistent with (P4), but that the implications of risk shifting at the same time seem to be inconsistent with (P3), 
the fact that workers who are laid off usually receive no income from their employer.

7. Unemployment Insurance

This section introduces tax-financed unemployment insurance, but abstracts from risk shifting. The analysis assumes that the unemployment insurance works as follows: A fund is financed by taxes and pay benefits to unemployed workers. The net transactions of this fund are the only difference between the aggregate value of current consumption and the aggregate value of current output. Only workers who are not proximately responsible for the change in their own status from employed to unemployed can receive benefits. Use of the administrative procedure (PI) satisfies this restriction.

The amount of the benefits received by an unemployed worker depends directly on his earnings when employed. -For the United States, the average replacement ratio of benefits, which until recently have not been taxable, to after-tax income seems to be slightly larger than onehalf--Feldstein (1978). For simplicitly, the analysis assumes * that average and marginal replacement ratios are equal. However, the analysis specifies that the amount of benefits would be reduced by the amount of any income that the unemployed worker received from his usual employer. This provision is apparently realistic and is crucial for the interaction, analyzed in the next section, between unemployment insurance and risk shifting.

For unemployment insurance to be actuarially "fair," the expected value of the taxes effectively paid to the unemployment insurance fund by each worker would have to equal the expected value of the net benefits he receives from the fund. It is possible that such an outcome would obtain if there were full experience rating in the calculation of each 
firm's contribution to the fund and benefits were taxed like other income. Actual unemployment insurance does not satisfy these conditions and apparently is actuarially favorable to workers who receive positive benefits and actuarially unfavorable to workers who do not receive benefits--Feldstein (1976). For simplicity, the analysis abstracts from taxes, except for the financing of the unemployment insurance fund.

The worker's problem now is to choose the vector $\left(l_{1}, l_{2}, \Omega_{1}, \Omega_{2}\right)$ so as to maximize $E(u-v)$, subject to the constraints

$$
\begin{aligned}
& \ell_{1}=\{0,1\}, \ell_{2}=\{0,1\}, \\
& c_{1}=(1-\tau) \Omega_{1}+b_{1} c_{2}=(1-\tau) \Omega_{2}, \\
& \Omega_{1}=w_{1} l_{1}, \Omega_{2}=w_{2} k l_{2}, \\
& b=\left\{\begin{array}{l}
\beta \Omega_{2}, \text { if } l_{2}=1 \text { and } \ell_{1}=0 \\
0, \text { otherwise, }
\end{array}\right. \\
& \tau=\left\{\begin{array}{l}
g, \text { if b }=0 \\
h, \text { otherwise, }
\end{array}\right.
\end{aligned}
$$

where $\tau$ is the effective tax rate on wage income for the unemployment insurance fund and $b$ is the amount of the unemployment benefit. According to these specifications, if an individual works only in the good state, $b$ equals $B \Omega_{2}$ and $\tau$ equals $h$. Otherwise, $b$ equals zero and $\tau$ equals g. Consumption in state two equals after-tax wage income. Consumption in state one equals either after-tax wage income or $b$.

Actuarially fair unemployment insurance would have $g$ equal to zero and $h$ equal to $B \alpha_{1} / \alpha_{2}$. As suggested above, 
it is probably more realistically to suppose that $g$ is positive and that $h$ is less than $\beta \alpha_{1} / \alpha_{2}$, which makes the system actuarially unfavorable to workers who are employed in both states and actuarially favorable to workers who are employed only in the good state.

The net replacement ratio is equal to $\beta /(1-h)$. We can easily calculate that unemployment insurance that was actuarially fair and complete, which would mean a net replacement ratio equal to unity, would have $g$ equal to zero, $h$ equal to $\alpha_{1}$, and $\beta$ equal to $\alpha_{2}$.

Depending now on $\alpha_{1}, \alpha_{2}, w_{1}, w_{2}, k, g, h$, and $\beta$, the solution to the worker's problem again can prescribe employment either in both states, only in the good state, or in neither state. In choosing among these options, the worker now selects the largest of the following possible values of $E(u-v)$ :

For employment in both states,

$$
E(u-v)=\alpha_{1} u\left[(1-g) w_{1} k\right]+\alpha_{2} u\left[(1-g) w_{2} k\right]-v(1) \equiv I(1,1) .
$$

For employment only in the good state,

$$
E(u-v)=\alpha_{1} u\left(\beta w_{2} k\right)+\alpha_{2} u\left[(1-h) w_{2} k\right]-\alpha_{1} v(0)-\alpha_{2} v(1) \equiv I(0,1) \text {. }
$$

For employment in neither state,

$$
E(u-v)=u(0)-v(0) \equiv I(0,0) \text {. }
$$

In comparing the worker's options with and without unemployment insurance, observe that $I(0,0)$ is identical to $A(0,0)$ and $S(0,0)$, and that, for actuarially fair and complete unemployment insurance and actuarially fair risk shifting, $I(0,1)$ is identical to $S(0,1)$ and larger than $A(0,1)$, and $I(1,1)$ is identical to $A(I, I)$ and smaller than $S(1,1)$. These relations mean that fair and complete unemployment insurance implies a range of values of $w_{2} k$ for which the worker chooses employment in neither state that is the same 
as with fair risk shifting, a range of combinations of $w_{1} k$ and $w_{2} k$ for which the worker chooses employment only in the good state that is larger than with fair risk shifting, and a range of combinations of $w_{1} k$ and $w_{2} k$ for which the worker chooses employment in both states that is smaller than with fair risk shifting. These results mean that the introduction of fair and complete unemployment insurance would cause fewer classes of workers to be employed in neither state of nature, more classes of workers to be employed in only one state of nature, and fewer classes to be employed in both states of nature, and that the latter two effects are larger than would result from the introduction of fairrisk shifting.

Extensions of these results are straightforward. Given actuarially fair unemployment insurance, making the net replacement ratio less than unity--which would mean $g=0, h=\beta \alpha_{1} / \alpha_{2}$, but $h<\alpha_{1}$ and $\beta<\alpha_{2}$-would reduce $I(0,1)$ and, hence, reduce the increase in the variability of employment. Alternatively, given complete unemployment insurance, making taxes actuarially favorable to individuals whose employment is variable--which would mean $\beta=1-h$, but $h<\alpha_{1}$ and $\beta>\alpha_{2}$--would raise $I(0,1)$, and making taxes actuarially unfavorable to individuals whose employment is constant--which would mean $g>0$--would reduce $I(I, I)$. Both of these changes would boost the increase in the variability of employment.

It is worth noting that the effect of actuarially fair unemployment insurance on the variability of employment depends on workers' being risk averse. If workers were not risk averse, unemployment insurance would make employment more variable only if it were actuarially favorable to workers who are employed only in the good state, as in Feldstein (1976), or actuarially unfavorable to workers who are employed in both states. 
This analysis also confirms that focusing only on unemployment insurance does not provide an adequate model of layoffs, because, although it is consistent with (PI), (P3), and ( $P 4)$, this analysis cannot account for (P2). Specifically, in this section, the actual wage rate and income received by a worker who is employed in both states varies with the value of his marginal contribution to output.

8. Risk Shifting and Unemployment Insurance

This section combines the analyses of the previous two sections to consider the interactions between risk shifting and unemployment insurance. With both risk shifting and unemployment insurance available, the worker's problem is to choose the vector $\left(l_{1}, l_{2}, \Omega_{1}, \Omega_{2}\right)$ so as to maximize $E(u-v)$, subject to the constraints

$$
\begin{aligned}
& \ell_{1}=\{0, I\}, l_{2}=\{0,1\}, \\
& c_{1}=(I-\tau) \Omega_{1}+b_{1} c_{2}=(I-\tau) \Omega_{2}, \\
& p \alpha_{1}\left(\Omega_{1}-w_{1} k l_{1}\right)=\alpha_{2}\left(w_{2} k l_{2}-\Omega_{2}\right), \\
& b= \begin{cases}\beta \Omega_{2}-\Omega_{1}, \text { if } l_{2}=1 \text { and } l_{1}=0 \\
0, \text { otherwise, }\end{cases} \\
& \tau= \begin{cases}g, \text { if b }=0 \\
h, \text { otherwise. }\end{cases}
\end{aligned}
$$

This set of constraints creates the complication that a worker who chooses employment in the good state and unemployment in the bad state has the alternative of receiving income in the bad state either from risk-shifting arrangements with his employer or from unemployment insurance benefits. Note that, because benefits are paid only to replace lost income, this worker has no motivation to choose a combination 
of risk shifting and unemployment insurance benefits. If he chooses risk shifting, his net income is $(I-g) \alpha_{2} w_{2} k /\left(p \alpha_{1}+p I / r \alpha_{2}\right)$

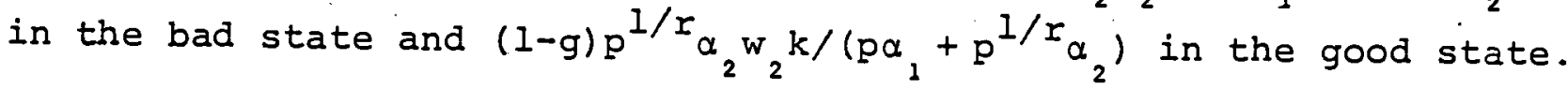
If he chooses unemployment insurance, his net income is $(I-h) w_{2} k$ in the good state and $B w_{2} k$ in the bad state.

If risk shifting were actuarially fair--i.e., $p=1$--and unemployment insurance were actuarially fair and complete--i.e., $g=0$ and $h=B \alpha_{1} / \alpha_{2}$--these alternatives would both provide constant net income equal to $\alpha_{2} w_{2} k$ and would be equally attractive. However, as discussed above, $p$ actually seems to exceed unity, which makes risk shifting less attractive, and actual unemployment insurance is incomplete but seems to be actuarially favorable to unemployed workers, characteristics that have offsetting effects on its attractiveness. These considerations suggest that it is reasonable to suppose that workers who choose employment only in the good state find unemployment insurance to be preferable to risk shifting. Note, however, that even if such workers find risk shifting unattractive relative to unemployment insurance, risk shifting remains attractive in reducing income variability for other workers who choose to " be employed in both states.

Under these conditions, the worker now selects the employment status that corresponds to the largest of the following possible values of $E(u-v)$ :

For employment in both states,

$$
\begin{aligned}
E(u-v) & =\alpha_{1} u\left[(1-g) \frac{p \alpha_{1} w_{1} k+\alpha_{2} w_{2} k}{p \alpha_{1}+p^{I / r_{\alpha_{2}}}}\right]+\alpha_{2} u\left[(1-g) p^{I / r} \frac{p \alpha_{1} w_{1} k+\alpha_{2} w_{2} k}{p \alpha_{1}+p 1 / p_{\alpha_{2}}}\right] \\
& -v(1) \equiv S I(1,1) .
\end{aligned}
$$


For employment only in the good state,

$$
E(u-v)=\alpha_{1} u\left(\beta w_{2} k\right)+\alpha_{2}\left[(I-h) w_{2} k\right]-\alpha_{1} v(0)-\alpha_{2} v(I) \equiv S I(0, I) .
$$

For employment in neither state,

$$
E(u-v)=u(0)-v(0) \equiv \operatorname{SI}(0,0) \text {. }
$$

In evaluating the worker's options with both unemployment insurance and risk shifting, observe that $S I(0,0)$ is identical to $I(0,0)$, that $S I(0, I)$ is identical to $I(0,1)$, and that $S I(1,1)$ is larger than $I(1,1)$. These observations imply that the range of values of $\mathrm{w}_{2} \mathrm{k}$ for which the worker chooses employment in neither state is the same with both unemployment insurance and risk shifting as with only unemployment insurance, but that the range of combinations of $w_{1} k$ and $w_{2} k$ for which a worker chooses employment in both states is larger with both unemployment insurance and risk shifting than - with only unemployment insurance.

These results enable us to draw the following two conclusions: First, although the introduction of risk shifting into a model without unemployment insurance would tend to magnify employment fluctuations, the actual effect of risk shifting in economies that have unemployment insurance is probably to make employment less variable. This result obtains as long as unemployment insurance is more attractive than risk shifting for most workers as a way to obtain income during states of unemployment. Under these conditions the availability of risk shifting does not make unemployment any more tolerable, but it does make stable employment more attractive.

Second, allowing for the effects of both risk shifting and unemployment insurance enables us to account for the full set of diverse phenomena associated with layoffs. The 
administrative assignment of workers, (PI), results from the fact that risk shifting makes wage income unequal to the value of product and/or from the eligibility rules for unemployment insurance benefits. The constancy of wages for employed workers, ( $P 2)$, directly reflects risk shifting. The fact that workers who are laid off usually receive no income from their employer, (P3), results from the attractiveness to them of unemployment insurance relative to risk shifting. Finally, the role of seniority in determining the incidence of layoffs, ( $P 4)$, reflects the relation between age and length of service and productivity.

\section{General Implications}

As indicated by the preceding paragraph, this paper has developed explanations for the phenomena associated with layoffs without reference to a failure of labor markets to clear and a loss of perceived gains from trade. This analysis - implies that, although a laid-off worker might want to work if offered either the wage rate he received when he was employed or the wage rate inclusive of insurance indemnity received currently by more senior workers who are employed, he would typically not want to work at the wage rate equal to the perceived value of his marginal product. Thus, the use of layoffs to effect employment separations does not imply that the amount of employment is suboptimal relative to current perceptions.

This interpretation of layoffs suggests that, as mentioned above, it may be realistic to attribute the causal relation between aggregate demand and aggregate employment to misperceptions of the exchange ratio between consumption goods and labor services, resulting from the limited ability of economic agents to distinguish aggregate disturbances from relative disturbances, rather than to an alleged failure of markets to clear. Other 
recent work incorporating risk shifting arrangements into the paradigm of incomplete information supports this point of view. For example, Grossman (1979) shows that the existence of risk-shifting arrangements in labor markets strengthens the substitution effects that influence the choice of-the efficient level of employment, implying that only weak restrictions on worker utility functions are necessary for changes in current nominal marginal products relative to perceived prices or expected future marginal products to have a strongly positive effect in employment. Finally, it is worth stressing again that emphasizing the failure to perceive gains from trade correctly does not mitigate in any way the wastefulness of non-Walrasian fluctuations in aggregate employment and the undesirability of monetary and fiscal policies which produce fluctuations in aggregate demand. 


\section{REFERENCES}

C. Azariadis, "Escalator Clauses and the Allocation of Cyclical Risks," Journal of Economic Theory, 18, June, 1978, 119-155.

M.N. Baily, "On the Theory of Layoffs and Unemployment," Econometrica, 45, July, 1977, 1043-1063.

R.J. Barro, "Long-Term Contracting, sticky Prices, and Monetary Policy," Journal of Monetary Economics, 3, July, 1977, 305-316.

R.J. Barro and H.I. Grossman, Money, Employment, and Inflation, (New York: Cambridge University Press, 1976).

M. Feldstein, "Temporary Layoffs in the Theory of Unemployment," Journal of Political Economy, 84, October, 1976, 937-957.

M. Feldstein, "The Effect of Unemployment Insurance on Temporary Layoff Unemployment," American Economic Review, 68, December, 1978, 834-846.

M. Friedman, "The Role of Monetary Policy," American Economic. Review, 58, March 1968, 1-17.

H.I. Grossman, "Risk Shifting and Reliability in Labor Markets," Scandinavian Journal of Economics, 79 , No. $2 / 1977,187-$ 209.

H.I. Grossman, "Risk Shifting, Layoffs, and Seniority," Journal of Monetary Economics, 4, November, 1978, 661-686.

H.I. Grossman, "Incomplete Information, Risk Shifting, and Employment Fluctuations," unpublished manuscript, April, 1979.

R.E. Lucas, Jr., "Understanding Business Cycles," in K. Brunner and A. Meltzer, eds., Stabilization of the Domestic and International Economy, (New York: North Holland, 1977), 7-29. 